\title{
Strength Evaluation of Marine Crane Hooks by Static-load and
}

\section{Fatigue Experiments*}

Toshihisa Nishioka**, Ho-yeon Lee ${ }^{* *}$, Young-jun Won **, Takehiro Fujimoto**

It is very important to evaluate the strength of marine hooks in order to prevent accidents. Thus, the authors studied the strength of marine crane hooks, which are widely used for marine cargo handling, by static-load and fatigue experiments. From the results of static load and cyclic load tests, it was confirmed that the strength of the crane hook was more sensitive to diameter change than the rounding, and its fatigue life was also more sensitive to a diameter change than a rounding change.

\section{Introduction}

Recently, many types of crane hooks are widely used in construction sites and industrial sites. M oreover, crane hooks are being used for not only freight transportation and loading but also performing internal repairs on ships. Fig.1 shows a crane hook that is used for repairs on a ship. While crane hooks are widely used, they are also prone to frequent damage and fracture.

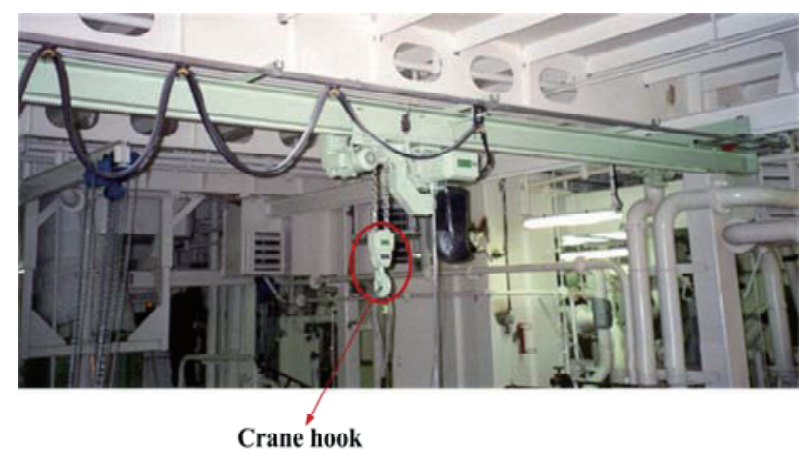

Fig.1 Overhead crane hook for ship

Though it is appropriate to consider the safe working load of a crane hook, it is not possible to do this on site. That is to say, crane hooks are often operated with loads that exceed its safe working load, because operators at sites assume that the

*Received April 8, 2010

**Graduate School of Maritime Science, Kobe-University crane hook can handle these loads on the basis of previous experience. A crane hook experiences transformation in such working environments and ideally, it should be replaced immediately as soon as small transformation and damage become apparent. The crane hook is indispensable for the protection safety, and repair of articles on ships. However, violation of safety requirements while handling crane hooks can cause a catastrophic loss of life and property. Therefore, both the hook operators and the manufacturers have to pay careful attention to the condition of the crane hooks in order to ensure safety of workers.

As the crane hook has come into wide use, and the regulation control for the crane user has been eased in J apan. The use of the hook up to the safe working load became possible even by the person who did not have a special license. Therefore, the person who does not especially have the knowledge and experience of the structure strength will use the crane hook, and the case that the crane hook was not used according to the rules within the safe working load happened frequently. Already the accidents are arising. Therefore, more detailed knowledge is requested about the safety use, the strength evaluation, and the enhanced safety of the crane hook. With this background, in this study, static-load and fatigue experiments were carried out for a crane hook, which was widely used at construction sites, industrial sites, and on ships. Moreover the level of observable transformation at varying loads was investigated. 
These observations can be used to prevent the falling of loads during service and to minimize the risk to those people working in the dangerous conditions. Further, the database prepared on the basis this experiment can offer beneficial product information to the developer and the operator.

\section{Experimental Procedures}

\subsection{M aterial and Experiment equipment}

The specimens that were used for experiments were shown in Fig.2. Specimen (1) was previously used on site. The brachial region was often damaged when it was used. The diameter and rounding of the brachial region on Specimen
(2) were altered in order to carry out a test of the difference of the crane hook strength. Test equipment is shown in Fig.3. We identified points on Specimen (1), as show in Fig.3 (c-1), and the difference between the point-to-point distance before and after the experiments for all the points was measured. And we examined the characteristics of fracture and damage due to the load change on the hook. The material of specimen in the ball-bearing region (SCM 420) was different from the material in the brachial region (SCM 435).

The material used in the specimen corresponded well with the strength required for each part. The safe working load of the crane hook is 2.9 tons. As the safety rating is 5 , the maximum safe working load is 14.5 tons.

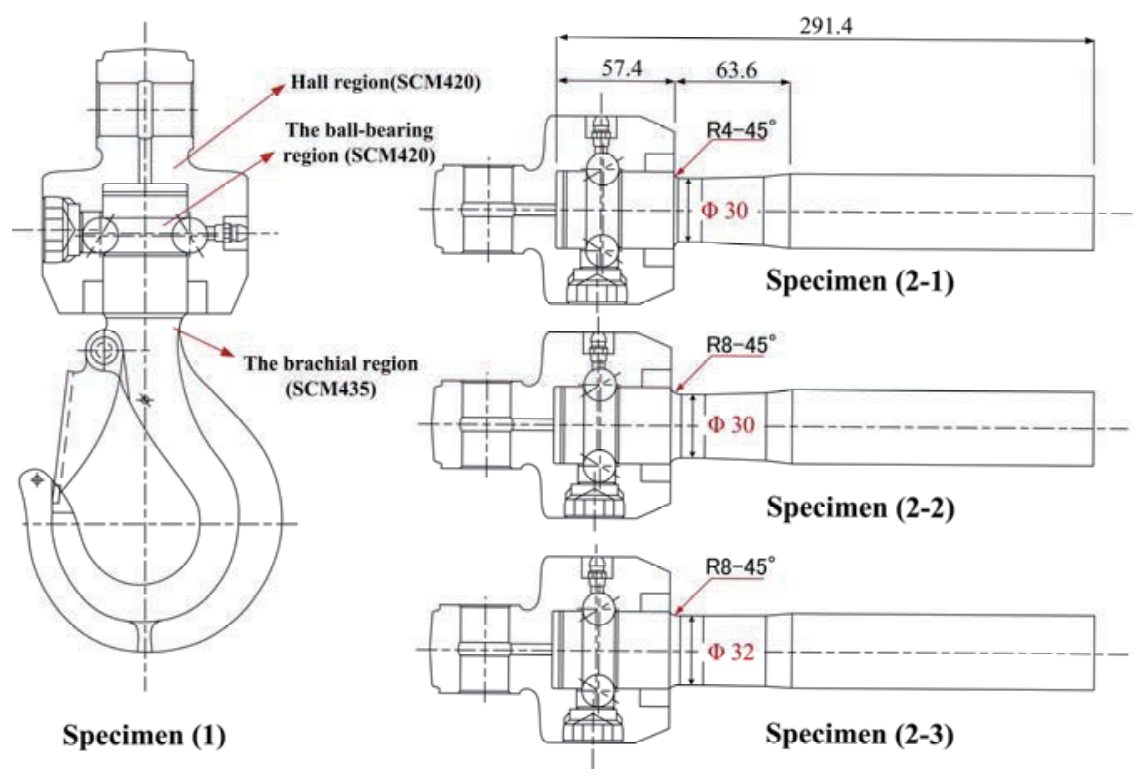

Fig.2 Shape of specimen

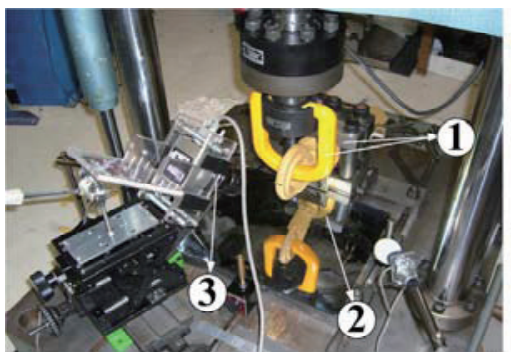

(a)

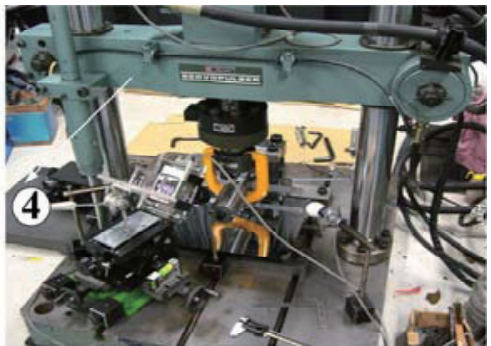

(b)

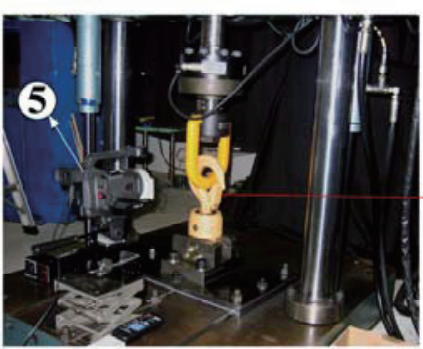

(c)

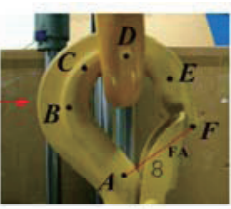

(c-1)

Fig.3 Test equipments 
The main experimental device (4) was used for the experiment on a hydraulic servo-type testing machine. The specimen was connected to the test machine using the jig-(1), as shown in Fig.3. The reflector-(2) is installed at the bottom to allow direct photography from different angles.

A CCD-camera-(3) and a VIDEO-camera-(5) were used for taking photographs of the experimental conditions and the crack growth behavior while the experiment is performed. Static loads of 15 tons and dynamic loads 10 tons could be applied for both tension loading and compressive loading during the experiment.

As the maximum safe working load of the crane hook is 14.5 tons. We can use the experiment machine for the safety evaluation of the crane hook.

\subsection{Experimental methods}

The loading modes are tension-tension and tension-compre -ssion. Fig.3-(a) shows that Specimen (1) was installed in the jig horizontally and connected with the main experiment machine using a link. Specimen (2) was installed the main experiment machine in a similar manner as shown in Fig.3-(b). We carried out the strength experiments under increasing static load and the crack growth behavior experiments under cyclic load. The static load experiment was displacement rate control method, and it was carried out under the following conditions; displacement rate $0.05 \mathrm{~mm} / \mathrm{s}$, maximum displacement $25 \mathrm{~mm}$, and experiment time $500 \mathrm{~s}$. The experiment was carried out three times each for Specimen (1) and Specimen (2) under the same conditions. Further, the cyclic-load experiment fatigue experiment was performed using the load control method at $2 \mathrm{~Hz}$ frequency and 0.1 stress ratio; the end time was determined as the time at which the specimen could no longer hold the maximum load. The test was carried out to examine the effect of the existence of grease in the lubrication part of the crane hook as well as the effect of different loads on the fatigue life of the crane hook. In addition, the effect of varying the diameter and rounding of the crane hook on the strength was examined. Fig.3-(c) shows that Specimen (1) was installed in the jig vertically for the other static load test; this position was implemented because crane hooks at construction sites generally operate on the load in the vertically position, as shown in Fig.3-(c). The Specimen marked with points A, B, $C, D$, and $E$, as shown in Fig.3 (C-1). The non-deformation lengths are as follows: $A B=65 \mathrm{~mm}, B C=30 \mathrm{~mm}, C E=64$ $\mathrm{mm}, \mathrm{EA}=65 \mathrm{~mm}$. A displacement rate control of $0.05 \mathrm{~mm} / \mathrm{s}$ was employed, and a tensile load was taken from upper part. The tensile load was taken until the load value reached the maximum safe working load (14.5 ton) of the hook. Thereafter, it was removed the tensile load that was taken, until the original load value ( 0 ton) was reached. The point-to-point displacement of the hook was observed for all the experiment processes.

\section{Results and Discussion}

\subsection{Results of static load}

Fig.4 shows the relationship between the load and displacement. As shown in Fig.4, the change of rounding did not affect the crane hook strength. From the comparison of the result of Specimen (2-2) and Specimen (2-3), on the other hand, it was confirmed that the diameter of crane hook affected its strength. From these results, we can conclude that the strength of the crane hook was more sensitive to a change in the diameter than the rounding. The initial crack occurred at 10.66, 17.14, and $19.61 \mathrm{~mm}$ from the starting point of displacement as shown in Fig.4. The starting point initial crack appeared at difference of the displacement. This difference might probably be attributed to the fact that the difference was evaluated using the data from the picture obtained by using the reflector.
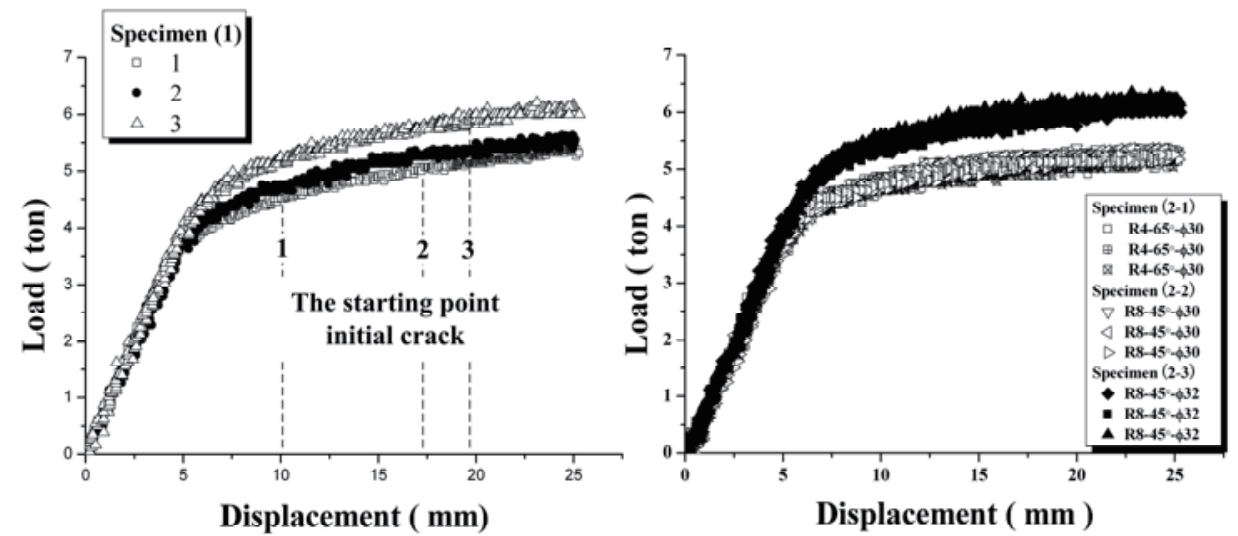

Fig.4 Relationship between load and displacement for static load 

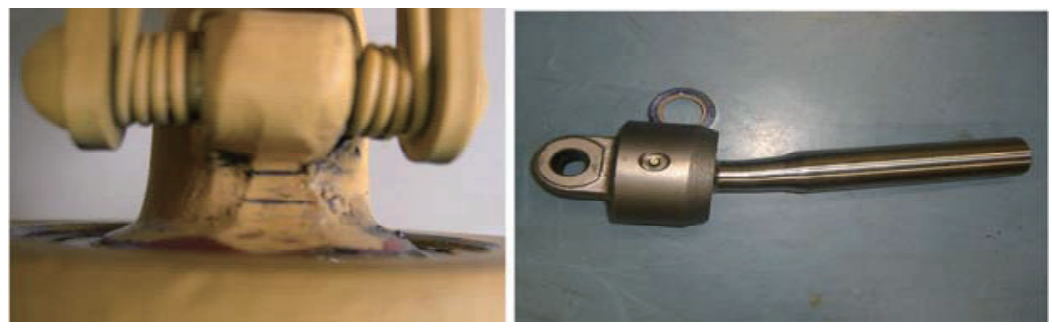

Fig.5 Shape of specimen after end of experiment

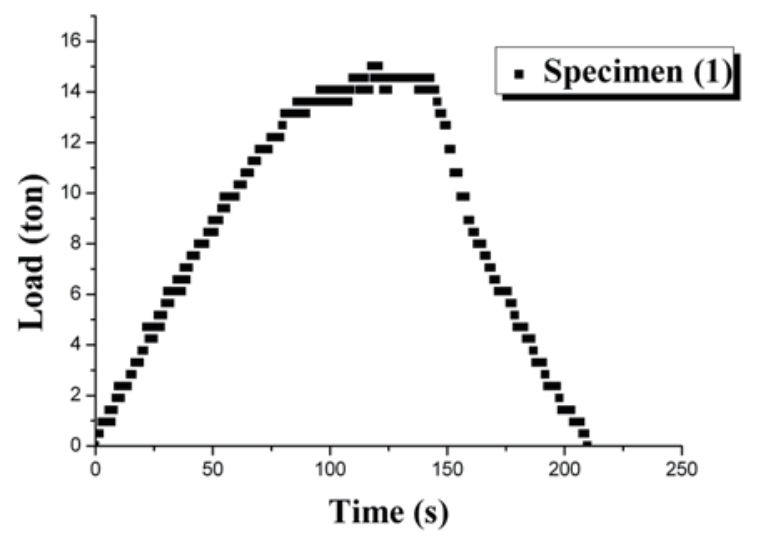

Fig.6 R elationship between load and time for static load
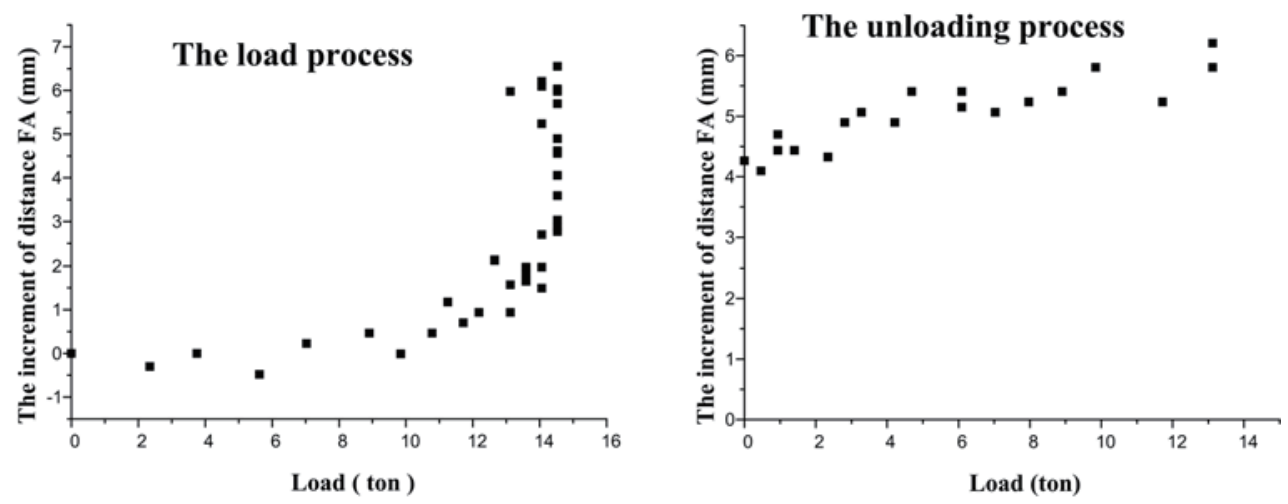

Fig.7 Relationship between increment of distance FA and load for static load

Fig.5 shows the shape of the specimen after the completion of the experiment. As shown in Fig.5, in Specimens (1), the crack originated in the brachial region, which is quite a dangerous development, and propagated from this initial position. On the other hand, no cracks were observed for Specimen (2). In the Specimen (2), we could only confirm the change in displacement.

Fig. 6 shows the relationship between load and time for static load. As shown in Fig.6, the linear relation between time and load deviates at the 12 ton load. This fact suggests that a plastic deformation occurs in the hook at the 12 ton load. In addition, Fig.7 indicates that the increment of the distance FA increases remarkably for the near 12 ton load, where the plastic deformation first occurred. In the unloading process, the increment of distance FA decreases. The removal of the load causes a reduction in the elastic strain of the hook; this reduction is due to the diminution of the elasto-plasticity deformation that occurred in the hook. As a result, the increment of distance decreases with the reduction in load.

3.2 Results of cyclic load on Specimen (1)

We carried out fatigue experiments on Specimen (1) to observe how the existence of grease affects the crane hook strength and the fatigue life. Fig.8 shows the fatigue experiment results; in this figure, it is possible to confirm the relationship between existence of grease and fatigue life. As shown in Fig.8, the initial crack started later in the specimen without grease, and the fatigue life was slightly longer. It 
was confirmed that the existence of grease does not affect the fatigue life. However, the longer fatigue life for the specimen without grease can be attributed to the fact that during the course of the experiment, the stress on the specimen with grease was more than the specimen without grease. Further, Fig.8 shows the fatigue life as a function of the load difference. Fatigue life reduced with increasing load. M oreover, the crane hook had roughly the same fatigue life in the cases of similar load. When comparing the difference in the fatigue life of specimens with loads of 3.6 tons and 2.9 tons, we found that the 2.9 tons specimen had an approximately 2.36 times longer fatigue life.
Further, the initial crack in the 3.6 tons specimen was approximately 2.48 times larger than that of the 2.9 ton specimen. Fig. 9 shows the fracture shape of the specimen (1) with grease and without grease after the completion of the fatigue experiments. The crack originated in the brachial region, and propagated from this initial position. The fatigue crack surface patter is similar to the specimen (1) with grease and without grease.

Consequently, we can conclude that the fatigue strength of crane hook was affected more by the load than by the existence of grease.
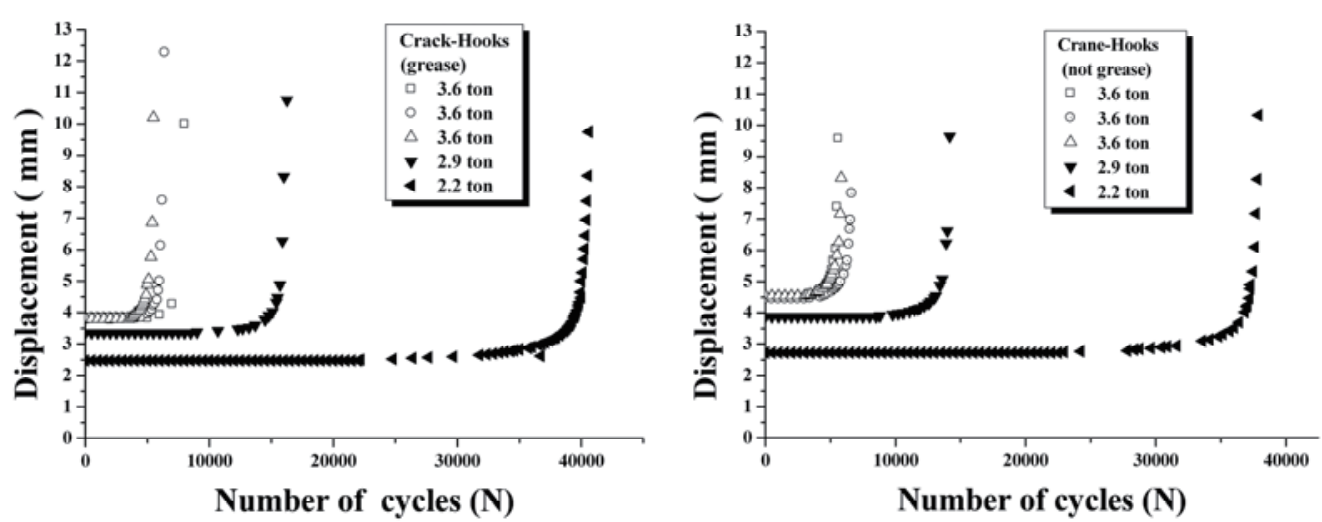

Fig.8 Relationship between existence of grease and fatigue life in the crane-hook

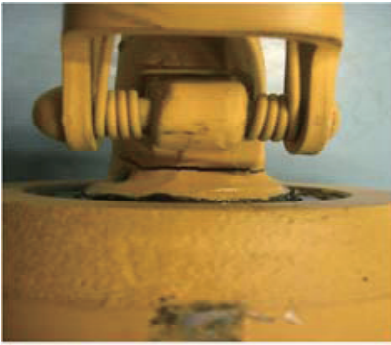

1) with grease (3.6 ton)

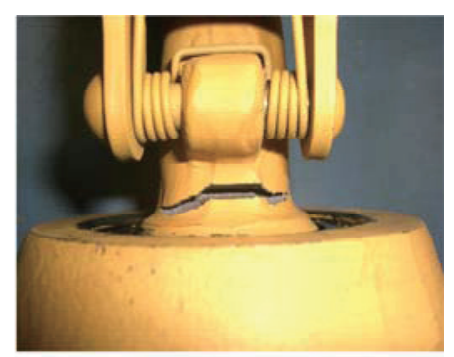

2) without grease (3.6 ton)

Fig.9 Fatigue fracture shape in the crane-hook

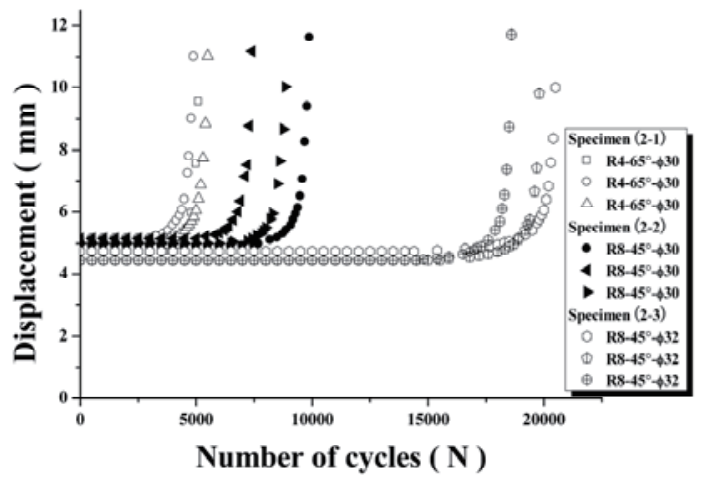

Fig.10 D-N curve in the specimen (2)-(3.6ton) 
3.3 Results of cyclic load on Specimen (2)

We carried out fatigue experiments on Specimen (2). Specimen (2) was modified by changing the rounding and diameter of the brachial region, where damage and fracture are frequent. Fig. 10 shows the $D-N$ curve based on the result of a fatigue test. Specimen (2-1) and Specimen (2-2) had modified rounding. As shown, the fatigue life for Specimen (2-2) was approximately 1.69 times longer than that for Specimen (2-1). Specimen (2-2) and Specimen (2-3) were also modified by changing their diameter. The fatigue life for Specimen (2-3), which had the larger diameter, was about 2.25 times longer. Consequently, we can conclude that the fatigue life of the crane hook is more sensitive to a diameter change than a rounding change.

\section{Conclusions}

The damage and fracture at the brachial region, which is a critical section of the crane hook, is closely connected to the diameter and the working load. With this in view, in this study, we carried out static-load and fatigue experiments with crane hooks that are used at construction sites and industrial sites.

The following are the results of our experiment;

(1) From the results of static load, it was clarified that the strength of crane hook was more sensitive to a change in the diameter than the rounding.

(2) From the results of cyclic load, it was confirmed that the fatigue strength of crane hook was affected by the load, and the existence of grease in the lubrication part of crane hook did not affect the fatigue strength.

(3) It was confirmed that fatigue life of crane hook was more sensitive to a diameter change than a rounding change.

(4) When an operator uses the crane hook at loads that are less than the safe working load, the crane hook can be used safely for a long period of time.

\section{References}

[1] "Failure of a large ball bearing of a dockside crane", Wouter O., Patrick D., Wim D., Engineering FailureA nalysis, Vol.11 N o.3, pp.335-353,(2004)

[2] "Development of a Workload A ssessment M odel for Overhead crane Operation", O chae K ., Sangki L., Y oungseok C., Jungchul P. and Kihyo I., J ournal of the Ergonomics Society of K orea, Vol.26 No.2, pp.45-59(2007)

[3] "Controller Design for an Overhead crane system with Uncertainty ", Chi-Cheng C. and Cheng-Y i C., Control Eng. Practice, Vol.4 No.5, pp.645-653, (1996) 